\title{
A Measurement Model of Depressive Symptoms among Older, African American Women
}

\author{
Tamika Baldwin-Clark, PhD, LCSW-S \\ Assistant Professor \\ College of Arts and Sciences \\ Prairie View A\&M University \\ United States of America \\ Jackson de Carvalho, PhD \\ Associate Professor \\ Prairie View A \& M University \\ Prairie View, Texas 77446 \\ United States of America
}

\begin{abstract}
For more than four decades, researchers have found depression to be a common mental illness among the elderly. Depression is a generalized mood disorder characterized by feelings of sadness and hopelessness, a sense of worthlessness, difficulty concentrating, loss of interest, and decrease in energy level. This definition is reflected in the Geriatric Depression Scale (GDS). The rates of depression among elderly residents of institutions are 67\% higher than among elderly adults residing at home. As in the United States, elderly women are twice as likely to be diagnosed with depressive symptoms as elderly men.. Time and again, research has revealed that depression is a significant problem for individuals later in life and may affect their psychological well-being. Using data from the Health and Retirement Study (HRS) 2010 wave, a secondary analysis was conducted to examine depression among community-dwelling, African American women, age 50 and over, as it relates to age, social support, religion, caregiving, and physical health. Intersectionality and social construction were used as theoretical frameworks for the study. Findings indicated significant relationships between depression and age, social support, and physical health. However, depression is treatable with pharmacotherapy, psychotherapy or combination of both.The overall purpose of this study was to explore the factors that may predict depression among older African American females, as well as identify gaps in the literature and add to the knowledge base about depression among this population of color, and develop a framework for future studies investigating mental health issues among diverse populations beyond African Americans.
\end{abstract}

Keywords:African Americans, women, older adults, depressive symptoms and research

\subsection{Introduction}

The elderly population has been growing very quickly across the world. According to the Administration on Aging (2016) the number of people in the United States aged 65 and over was 49.2 million, representing about $15.1 \%$ of the total population (Department of Health and Human Services, 2012). This figure is likely to increase to $20.3 \%$ by 2050 (Winner \& Tilly, 2012). For more than four decades, researchers have found depression to be a common mental illness among the elderly (Charatan, 1975; Sreevani \& Reddemma, 2012). The rates of depression among elderly residents of institutions are $67 \%$ higher than among elderly adults residing at home (Al-Jawad, Rashid, \& Narayan, 2007). As in the United States, elderly women are twice as likely to be diagnosed with depressive symptoms as elderly men (Salimah, Rahmah, Rosdinom, \& Azhar, 2008).

Depression has been considered variously as both an illness and a syndrome (Salimah et al., 2008). In the early 20th century, depression was known as melancholia (Berrios, 1988). Later in 1980, the term depression was used and incorporated in the Diagnostic Statistical Manual Three (DSM-III) under organic affective syndrome and adjustment disorder (American Psychiatric Association, 1987). Upon revision, most of the depressive symptoms in the DSM III were categorized under mood disorders. As described by the latest Diagnostic of Statistical ManualFifth Edition (DSM-5) depression is one of the mood disorders associated with the presence of depressed mood or loss of interest on daily activities that occurs every day for most of the day for at least two weeks (American Psychiatric Association, 2013).

Depression is also considered as a syndrome or a cluster of symptoms, behaviors, and functional disturbance that is characterized by changes in appetite (either increase or decrease), difficulties with sleep pattern, difficulty in concentration, and retarded or increased psychomotor functions (American Psychiatric Association, 2013). 
The existence of psychological symptoms such as feeling of worthlessness, hopelessness, 32 indecisiveness, guilt feelings, feeling of anger, and suicidal ideation also reflects the common symptoms of depression (World Health Organization, 2012). Consistent with the definition provided by the DSM-5 the International Classification of Disease-Version Ten (ICD-10) (2010), which is used to define depression as a situation when individuals experience consistent reduction of energy, decreased ability to enjoy interested activities, an increased in social withdrawal, and recurrent deep sadness without valid reasons. These symptoms may cause dysfunction in an individual's physical and mental health and could impair an individual's ability to take care of one's self and fulfill daily responsibilities.

The depressive symptoms are usually much worst in the mornings as compared to other times in the day, which makes it harder for an individual to begin his or her day with a fresh start. The World Health Organization (2013) considers depression as a serious mental disorder that affects 340 million people across the world. As compared to other mental disorders, depression is considered the most prevalent illness in the world, which is estimated to affect 350 million people (WHO, 2013). It is expected to be the second most prevalent worldwide illness after ischemic heart disease by the year 2020 (Abdel-Rahman, 2012). At least 25\% of all adults worldwide experience depressive symptoms at least once during their lifetime, and depression does not discriminate. It affects all age groups, from children to the elderly. More seriously, depression has been associated with significant high morbidity and mortality among older adults (WHO, 2013).

The overall purpose of this study was to explore the factors that may predict depression among older African American females, as well as identify gaps in the literature and add to the knowledge base about depression among this population of color, and develop a framework for future studies investigating mental health issues among diverse populations beyond African Americans. Specifically, the research questions addressed in this study probed (a) the relationship between age and depression, (b) the influence of social support on depression, (c) the relationship between religion and depression, (d) the relationship between caregiving and depression, (e) the influence of physical health on depression, and (f) the joint impact of age, social support, religion, caregiving, and physical health on depression.

Answering these questions will have a significant influence on the way mental health services are provided to this population and the way in which research is implemented in the field of social work through practice and policy. The manner in which social work researchers are trained and educated must be adjusted to include these factors, based on the findings of this study and other similar studies. Knowledge of these relationships may help researchers create targeted interventions designed to reduce the prevalence of depressive symptoms in older African American women (Centers for Disease Control and Prevention (2018). Although there have been many studies comparing older Black and White populations, this study focused specifically on the factors of older, community-dwelling, African American women.

\subsection{Review of Literature}

Depression is a generalized mood disorder characterized by feelings of sadness and hopelessness, a sense of worthlessness, difficulty concentrating, loss of interest, and decrease in energy level. This definition is reflected in the Geriatric Depression Scale (GDS) (Bluth, Campo, Futch, \& Gaylord, 2016).In the United States, the elderly is categorized as those aged 65 and older. This categorization follows the age classification used by the Administration on Aging (2012). In 2018, life expectancy at birth for males was 73 years and 78 years for females (Centers for Disease Control and Prevention, 2018). The U.S. Department of Health and Human Services (2018)projected that in 2025, the life expectancy will increase to 77.7 years for males and 83.1 years for females. The projected increase in the number of elderly population and their life expectancy shows the possibility of having new age categorization in the future, where the elderly could be define as those who age 70 years and above.

The main developmental task for an elderly person is to reflect upon and integrate one's life in the face of loss and subsequent death (Erikson, 1982). Facing the reality of aging that is impossible to hide is sometimes painful and challenging to some elderly. The elderly adult who is able to own her life experiences including accepting her failures, frustrations, and unsuccessful life stories is found to be happier in life compared to the elderly adult who is afraid and anxious when facing the end of life changes.One study conducted with 151 elderly people in institutions, on their attitude towards aging, found that elderly who had negative attitudes and refused to accept the reality of aging showed more depressive symptoms and reported to have low life satisfaction (Rashid, Ong \& Wong, 2012).Depression is a challenging mental health illness. It can cause tremendous and unbearable amount of suffering on the elderly, their families, and friends who must cope with the 19 uncertainties of care and outcomes of depression. This situation is normally the case when depression is not properly addressed. At the same time, society also has to bear heavy social consequences as well as higher economic cost in dealing with the effects of depression on elderly's well-being (Bschor, Bauer, \& Adli,2014). 
Depression among the elders is one of the most common and significant mental health issues among people around the world (Bluth et al., 2016; CDC, 2018; Davey-Rothwell, Stewart, Vadnais, Braxton, \& Latkin, 2017; Rashid, Ong \& Wong, 2012; WHO, 2018), yet it is often seen as inevitable specifically among older adults of color (Sriwattanakomen et al., 2010; Zalaquett \& Stens, 2006). Although there is an abundance of research on depression, most of the research tends to relate to majority cultures. Subsequently, there is a limited amount of information focusing on older African American women and their experiences with depression.

Several studies have been conducted on the predictors of psychological well-being among the elderly. About 1415 respondents aged 60-100 years consisting of 722 women and 693 men participated in a nationwide survey to determine socio-demographic predictors of psychological well-being among the elderly (Momtaz, Ibrahim, Hamid \& Yahaya, 2011). Their findings showed that age, gender, marital status and household income were significant predictors of psychological well-being among the elders. They also found that the lower the age of the respondents the higher the psychological well-being. In addition, the same study also found that the older women reported to have lower levels of psychological well-being as compared to older men and married respondents were reported to have better psychological well-being as compared to the unmarried.

Respondents with higher income reported to have higher psychological well-being. In terms of employment status and educational achievement, the researchers reported some effects on the respondents even though it was not statistically significant. They found that retired and employed respondents or groups tended to have higher psychological well-being than the unemployed group. Also, those who were in the secondary education group scored higher than the primary and the no-formal education groups. This means the higher the education the better the psychological well-being of the elderly (Momtaz, Ibrahim, Hamid \& Yahaya, 2011).

Besides the above predictors, individuals' psychological well-being also depends on their interactions with social environment. Study on the association between social relationships and well-being in old age is an important undertaking. Social relationships are believed to affect elderly's psychological well-being and their quality of life (Hsu \& Tung, 2010). A study on quality of relationships showed that social affiliation is highly related to psychological wellbeing, whereas loneliness has the opposite sides (Momtaz et al., 2011). The same study also revealed that it is the quality not the quantity of relationships that was related to psychological well-being. In addition to the above findings, social support from friends, spouse and neighbors are reported to have a significant influence on elderly life satisfaction and psychological well-being (Bluth et al. (2016).

\subsection{Theoretical Framework}

Throughout the literature, several theoretical perspectives are used to analyze this social problem, including the life course perspective, psychology of religion, stress and coping model, and social cognitive theory. More than one theory is often used concurrently to examine depression among African Americans (Black, Gitlin, \& Burke, 2011). Given their unique history in the United States and their continued plight and circumstances, it is important to look at older African American women from varying perspectives. The major theoretical perspectives used to guide this study were social construction theory and intersectionality. These perspectives do not entirely explain depression among older African American women; however, they do offer an overarching framework for better understanding the factors connected to depression within this group (Black et al., 2011).

The theory of social construction is used primarily in the social sciences and humanities disciplines but also has been adopted by other disciplines such as business studies (Otubanjo, 2012). Berger and Luckmann introduced the term "social construction" in 1966 as a means to describe the way in which individuals and groups construct their own realities given their social, cultural, and historical contexts (Otubanjo, 2012). They observed that all knowledge and understanding of the world comes from social interactions, as opposed to reasoning and experimentation (Otubanjo, 2012; Payne, 2005). The social construction theory seeks to examine how social phenomena and trends develop into customs and beliefs about the changing processes within the society (Otubanjo, 2012). This interpretivist postmodernist theory, along with reflective and intentional theories, is a part of cultural representation theories and is linked to social psychology and social constructivist theory (Otubanjo, 2012; Payne, 2005).

Social workers use the social construction theory as a basis for psychotherapy (Payne, 2005). In practice, social construction models respond specifically to clients' own views of their world and assessment of their problems. In research, human interactions, such as conversations, are systematically analyzed, often using video- and audiotaped recordings of interactions. These analyses help to reveal communication and behavior patterns that may be hidden (Payne, 2005).

Rooted in Black feminist scholarship, intersectionality is similar to the cumulative advantage/disadvantage theory, cumulative inequality theory, and the double/triple jeopardies perspectives (Bowleg, 2012; Crenshaw, 1991; Mair, 2010; Spence et al., 2011), which are also referred to in the literature as multiple-stratification or multiple-hierarchy stratification perspectives (Schieman \& Plickert, 2007). 
Although some scholars call it a theory or approach (Walby, Armstrong, \& Strid, 2012; Warner \& Brown, 2011), others refer to intersectionality as a unifying, interpretive, theoretical framework or perspective (Bowleg, 2012). Bowleg (2012) stated that intersectionality is not a traditional theory in that it does not have any basic principles or variables that can be measured operationally or empirically tested. It is more of an analytical framework or paradigm. Although previous studies using intersectionality have been mainly qualitative research, it is also important for quantitative research to take this approach into account as this approach speaks to the importance of gathering information about cultures, communities, and other factors that intersect with people's experiences (Warner \& Brown, 2011).

The term "intersectionality" was first coined by feminist legal scholar Kimberle Crenshaw during the 1990s (Bowleg, 2012). However, the idea has been around for more than a century. Abolitionist Sojourner Truth challenged the idea of viewing the social constructs of gender and race separately in her famous "Ain't I a Woman?" speech at the 1851 Women's Convention in Akron, Ohio (Bowleg, 2012). It illustrated how African American women have often had to choose between their rights as African Americans and their rights as women. Not having to choose one identity over another is crucial, as it is impossible for one to just be seen as an African American without the gender aspect and vice versa. Crenshaw also used the term to explain the exclusion of Black women from feminist discourse, which centers around White women, and antiracist discourse, which centers around Black men. Intersectionality is also used to examine the multiple, interlocking influences of various systems of oppression and privilege such as, sexism, racism, and ageism (Bowleg, 2012).

Social construction and intersectionality are complementary frameworks. The social constructionist theory views experiences, such as depression, as culturally and socially constructed (Black et al., 2011). Depression develops in a context, as opposed to developing independent of one's experience (Black et al., 2011; Black \& Rubinstein, 2009; Black et al., 2007). Older adults are the active creators of their own unique worlds and as the experts in explaining those worlds to other individuals (Black et al., 2011). Furthermore, the intersectionality perspective in aging research, especially quantitative aging research, is scarce, yet offers the ideal foundation for exploring the effect of various risk and protective factors on depression for African American women (Mair, 2010). As older African American women, the concept of depression varies by not only race/ethnicity, but also by gender and one's experiences of it. Adding age into the component makes for a more in-depth perspective, since older African American women are often society's least privileged group in terms of socioeconomic status and health (Black et al., 2007; Hunn\& Craig, 2009).

\subsection{Method}

Drawn from an original sample of 22,034 individuals, the sample for this research consisted of 2,249 respondents. HRS data from the 2010 wave were utilized, due to the data's availability. The National Institute on Aging and the Social Security Administration sponsor the HRS and the study is led by University of Michigan researchers. It is an ongoing, nationally representative, non-experimental, quantitative, longitudinal panel study of individuals, 50 years of age and older. The measures were drawn from the RAND HRS Data file (Version M), which is a cleaned version of the dataset. This dataset was chosen due to the oversampling of African Americans and the different measures of depression, as it relates to social support, religion, caregiving, and physical health, as well as, the demographic measure of age.

The original sample in 2010 consisted of 22,034 individuals. Of those 22,034 respondents, there were 9,231 (41.9\%) men and $12,803(58.1 \%)$ women. Of the 22,034 people in the study, 18,953 (86.0\%) did not consider themselves Hispanic or Latino. There were 4,284 (19.4\%) individuals who identified as black or African American. Drawn from the original pool, there were 2,249 living individuals who identified as black or African American (non-Hispanic nor non-Latina), female, were at least 50 years old, completed the interview themselves without a proxy, were not nursing home or other health care facility residents, and agreed to the interview in the sample.

\subsection{Instrument}

The Center for Epidemiologic Studies-Depression Scale (CES-D) instrument was used to evaluate one's depression (Aneshensel, Wight, Miller-Martinez, Botticello, Karlamangla, \& Seeman2007). In each of the waves of the study, respondents were asked about eight common symptoms of depression taken from the CES-D instrument (U.S. Department of Health and Human Services, 2007). In validation studies against the full CES-D battery, exhibiting four of eight symptoms is connected to being clinically depressed (U.S. Department of Health and Human Services, 2007). Telephone interviews and mail-in surveys were the methods of data collection. The two categories for this study, ever had depression and felt depressed in the past year, were based on questions from HRS that incorporated the CES-D scale. 
Confidentiality and anonymity of participants were strictly upheld. All data accessed were handled with the utmost care. Morgan State University's Institutional Review Board (IRB) approval was obtained prior to the beginning of the analysis, in order to confirm that the benefits of the study outweighed its risks and that it protected human subjects. Approval from the HRS was also obtained in order to use the data. The National Association of Social Workers' Code of Ethics were adhered to. Data were analyzed by the researcher, and all data accessed for this secondary analysis was discarded at the end of the study. The information was discarded by shredding all materials associated with the study

\subsection{Data Analysis}

SPSS version 20, a comprehensive statistical computer program, was used to analyze the data. Descriptive statistics were run first to tabulate the frequency of the two measures of depression in relation to the independent variables of age, social support, religion, caregiving, and physical health. Multiple logistic regression, which is defined as a statistical procedure for predicting a dichotomous dependent variable based on at least one independent variable, was used for the statistical analyses in order to examine the variables associated with the presence of depression (Levin, Fox, \& Forde, 2010; Steffens, Fisher, Langa, Potter, \&Plassman2009). The model building approach (i.e., step-wise, forward or backward elimination) was not used in this study, in order to show the relationship between all of the independent variables in this special population.

\subsection{Measures}

The purpose of this study was to examine risk and protective factors for depression among older African American women in the United States. This study was limited to examining self-identified, African American (nonHispanic), community-dwelling women, ages 50 and older. The intersectionality model and social construction theory were used to frame this study. Specific factors explored included age, social support, religion, caregiving, and physical health as risk and protective factors for depression among community-dwelling African American women. This chapter outlines the methodology for this study.

As stated previously, the research questions that guided this investigation were driven by an integrative perspective derived from theories and translational/intervention research that may heighten the research and practice relevancy of variables predictive of depression among community-dwelling older African American women. The integration of theories and research may offer the opportunity to develop specific recommendations for future research and practice. Whereas theoretical perspectives provide essential explanatory knowledge about the problem of depression among the elders, translational research attempted to apply such explanatory knowledge to interventions involving depression among older adults, particularly community-dwelling African American women.

Data collection began in 1992, when the Health and Retirement Study was first launched, and biennially thereafter (U.S. Department of Health and Human Services, 2007). Through a multi-stage clustered area probability sampling design, 69,336 households were selected (Mojtabai \& Olfson, 2004). Those born between 1931 and 1941, who were between 51 and 61 years old in 1992, were asked to participate in the study, with $78 \%$ consenting to participate (Mojtabai \& Olfson, 2004). Participants were first interviewed in person in 1992, then re-interviewed biennially (Warner \& Brown, 2011). Their spouses or partners, regardless of ages, were also included in the sample (Mojtabai \& Olfson, 2004). Following the first wave of in-depth interviews, the majority of interviews thereafter were conducted via phone (Mojtabai \& Olfson, 2004). Data for this analysis were extracted from the 2010 wave of the study.

SPSS version 20, a comprehensive statistical computer program, was used to analyze the data. Descriptive statistics were run first to tabulate the frequency of the two measures of depression in relation to the independent variables of age, social support, religion, caregiving, and physical health. Multiple logistic regression, which is defined as a statistical procedure for predicting a dichotomous dependent variable based on at least one independent variable, was used for the statistical analyses in order to examine the variables associated with the presence of depression (Levin, Fox, \& Forde, 2010; Steffens et al., 2009). The model building approach (i.e., step-wise, forward or backward elimination) was not used in this study because this study aimed to show the relationship between all of the independent variables in this special population.

\subsection{Results}

This article presents the results of the study of 2,249 Black and/or African American, non-Hispanic women, 50 years of age or older, who were not in nursing homes or other health care facilities. Six research questions guided this study. The results are organized as follows. First, a descriptive analysis of the data is presented. Secondly, an inferential analysis including a Chi-Square Analysis and a Logistic Regression of Ever Had Depression by Selected Independent Variablesfor women who ever had depression and women who felt depressed are presented. The independent variables are discussed in order of age, social support, religion, caregiving, and physical health. 


\subsection{Descriptive Analysis}

Table 1 shows the number of women for each of the independent variables in the sample. Over $47 \%(n=1,066)$ were in the 50-59 age group. There were $25.4 \%(\mathrm{n}=571)$ in the 60-69 age category. Among the social support variables, $31.8 \%(\mathrm{n}=715)$ were currently married, while $25.4 \%(\mathrm{n}=571)$ were widowed. Additionally, there were 94\% ( $\mathrm{n}=2,073)$ who reported that they did not currently receive help from relatives. The majority of the sample, $72 \%(n=1,565)$, had no relatives near. There were $52.5 \%(n=1,141)$ participants who reported having good friends near. When asked about how often the women get together with other people, 35\% $(n=754)$ reported that they almost never do, while 31.6\% $(n=680)$ reported that they get together with people at least on a weekly basis. About $82 \%(n=1,461)$ reported that they believe they have relatives and/or friends that would be able to help them with any future needs.

In terms of how often one attends religious services, $28.1 \%(n=630)$ of the sample reported attending more than once a week during the past year. Another $27.8 \%(n=623)$ stated that they attended religious services once a week during the past year. Furthermore, $92.5 \%(n=2,077)$ viewed religion as very important, while less than $2 \%(n=41)$ thought that it was not too important. Most women, 59.6\% ( $\mathrm{n}=1,058)$, did not report providing 100 or more hours of care to grand or great grandchildren since the previous wave. On a scale of 1 to $5,34 \%$ of participants gave themselves a rating of $3(n=765)$ for good health. About $20 \%(n=455)$ had ever experienced depression and conversely almost $80 \%(n=1,789)$ had never experienced depression, while $80.5 \%(n=1,808)$ reported that they had not felt depressed in the past year and 19.5\% $(n=437)$ stated they had felt depressed in the past year.

Table 1. Number and Percent of Women in the Sample by Age Group, Social Support, Religion, Caregiving, Physical Health, and Depression (cont'd.)

\begin{tabular}{lll}
\hline & Frequencies & \\
\cline { 2 - 2 } Independent Variables & $\mathrm{N}$ & \\
\hline Age Group: & & \\
$50-59$ & 1066 & 47.4 \\
$60-69$ & 571 & 25.4 \\
$70-79$ & 464 & 20.6 \\
$80-89$ & 121 & 5.4 \\
90 and Older & 27 & 1.2 \\
Total & 2249 & 100.0 \\
\hline Social Support: Marital Status & & \\
Never Married or Other & 316 & 14.1 \\
Widowed & 571 & 25.4 \\
Divorced & 504 & 22.4 \\
Separated & 143 & 6.4 \\
Married & 715 & 31.8 \\
Total & 2249 & 100.0 \\
\hline Receive Help from Relatives & & \\
No & 2073 & 94.0 \\
Yes & 132 & 6.0 \\
Total & 2205 & 100.0 \\
Relatives Near & & \\
No & 1565 & 72.0 \\
Yes & 608 & 28.0 \\
Total & 2173 & 100.0 \\
\hline Good Friends Near & & \\
No & 1032 & 47.5 \\
Yes & 1141 & 52.5 \\
Total & 2173 & 100.0 \\
\hline
\end{tabular}


Number of Times Get Together with People

Day

Week

Every Two Weeks/Bi-Weekly

Month

Year

Almost Never or Other

Total

\section{Relatives/Friends Help with Future Needs}

No

Yes

Total

Religion:How Often Attend Religious Services

Not at All

One or More Times a Year

Two or Three Times a Month

Once a Week

More Than Once a Week

Total

Importance of Religion

Not Too Important

Somewhat Important

Very Important

Total

Caregiving: Care of Grandkids-100 or More Hours

No

Yes

Total

1058

716

1774

315

1461

1776

246

328

418

623

630

2245

41

128

2077

2246

59.6

40.4

100.0
10.3

31.6

3.0

15.1

5.1

35.0

100.0

17.7

82.3

100.0

11.0

14.6

18.6

27.8

28.1

100.0

1.8

5.7

92.5

100.0

Physical Health:

Poor

Fair

212

649

765

482

Very Good

Excellent

Total

Dependent Variables

Ever Had Depression:

No

Yes

Total

Felt Depressed in Past Year:

No

Yes

Total
1789

455

2244

1808

437

2245
2247

N

9.4

28.9

34.0

21.5

6.2

100.0

$\%$

79.7

20.3

100.0

80.5

19.5

100.0 
Table 2. Chi-Square Analysis for Ever Had Depression by Selected Independent Variables

\begin{tabular}{|c|c|c|c|c|c|c|}
\hline \multirow[b]{2}{*}{ Independent Variables } & \multicolumn{6}{|c|}{ Ever Had Depression } \\
\hline & No N (\%) & Yes N (\%) & Total N (\%) & $\begin{array}{l}\text { Pearson Chi- } \\
\text { Square }\end{array}$ & $\mathrm{DF}$ & $\begin{array}{l}\text { P- } \\
\text { Value }\end{array}$ \\
\hline $\begin{array}{l}\text { Age Group } \\
90 \text { and Over } \\
80-89 \\
70-79 \\
60-69 \\
50-59 \\
\text { Total }\end{array}$ & $\begin{array}{l}25(92.6 \%) \\
98(81.0 \%) \\
402(87.0 \%) \\
468(82.0 \%) \\
796(74.9 \%) \\
1789(79.7 \%)\end{array}$ & $\begin{array}{l}2(7.4 \%) \\
3(19.0 \%) \\
60(13.0 \%) \\
103(18.0 \%) \\
267(25.1 \%) \\
455(20.3 \%\end{array}$ & $\begin{array}{l}27(100.0 \%) \\
121(100.0 \%) \\
462(100.0 \%) \\
571(100.0 \%) \\
1063(100.0 \%) \\
2244(100 \%)\end{array}$ & 35.254 & 4 & $* .0001$ \\
\hline $\begin{array}{l}\text { Social Support:Marital Status } \\
\text { Married } \\
\text { Separated } \\
\text { Divorced } \\
\text { Widowed } \\
\text { Never Married or Other } \\
\text { Total }\end{array}$ & $\begin{array}{l}607(85.0 \%) \\
109(76.2 \%) \\
383(76.0 \%) \\
458(80.6 \%) \\
232(73.7 \%) \\
1789(79.7 \%)\end{array}$ & $\begin{array}{l}107(15.0 \%) \\
34(23.8 \%) \\
121(24.0 \%) \\
110(19.4 \%) \\
83(26.3 \%) \\
455(20.3 \%)\end{array}$ & $\begin{array}{l}714(100.0 \%) \\
143(100.0 \%) \\
504(100.0 \%) \\
568(100.0 \%) \\
315(100.0 \%) \\
2244(100 \%)\end{array}$ & 25.265 & 4 & $* .0001$ \\
\hline $\begin{array}{l}\text { Social Support: Receive Help } \\
\text { from Relatives } \\
\text { No } \\
\text { Yes } \\
\text { Total }\end{array}$ & $\begin{array}{l}1661(80.3 \%) \\
91(68.9 \%) \\
1752(79.6 \%)\end{array}$ & $\begin{array}{l}407(19.7 \%) \\
41(31.1 \%) \\
448(20.4 \%)\end{array}$ & $\begin{array}{l}2068(100.0 \%) \\
132(100.0 \%) \\
2200(100.0 \%)\end{array}$ & 9.908 & 1 & $* .002$ \\
\hline $\begin{array}{l}\text { Social Support:Relatives Near } \\
\text { No } \\
\text { Yes } \\
\text { Total }\end{array}$ & $\begin{array}{l}1242(79.6 \%) \\
487(80.2 \%) \\
1729(79.8 \%)\end{array}$ & $\begin{array}{l}319(20.4 \%) \\
120(19.8 \%) \\
439(20.2 \%)\end{array}$ & $\begin{array}{l}1561(100.0 \%) \\
607(100.0 \%) \\
2168(100.0 \%)\end{array}$ & .120 & 1 & .729 \\
\hline $\begin{array}{l}\text { Social Support:Good } \\
\text { FriendsNear } \\
\text { No } \\
\text { Yes } \\
\text { Total } \\
\end{array}$ & $\begin{array}{l}803(78.0 \%) \\
927(81.3 \%) \\
1730(79.8 \%) \\
\end{array}$ & $\begin{array}{l}226(22.0 \%) \\
213(18.7 \%) \\
439(20.2 \%) \\
\end{array}$ & $\begin{array}{c}1029(100.0 \%) \\
1140(100.0 \%) \\
2169(100.0 \%)\end{array}$ & 3.602 & 1 & .058 \\
\hline $\begin{array}{l}\text { Social Support: Number of } \\
\text { Times Get Together with People } \\
\text { Day } \\
\text { Week } \\
\text { Every Two Weeks/Bi- } \\
\text { Weekly } \\
\text { Month } \\
\text { Year } \\
\text { Almost Never or Other } \\
\text { Total }\end{array}$ & $\begin{array}{l}177(80.1 \%) \\
545(80.3 \%) \\
56(87.5 \%) \\
\\
275(84.6 \%) \\
88(80.7 \%) \\
573(76.2 \%) \\
1714(79.7 \%)\end{array}$ & $\begin{array}{l}44(19.9 \%) \\
134(19.7 \%) \\
8(12.5 \%) \\
\\
50(15.4 \%) \\
21(19.3 \%) \\
179(23.8 \%) \\
436(20.3 \%)\end{array}$ & $\begin{array}{l}221(100.0 \%) \\
679(100.0 \%) \\
64(100.0 \%) \\
\\
325(100.0 \%) \\
109(100.0 \%) \\
752(100.0 \%) \\
2150(100.0 \%)\end{array}$ & 13.201 & 5 & $* .022$ \\
\hline $\begin{array}{l}\text { Social Support: } \\
\text { Relatives/Friends Help with } \\
\text { Future Needs } \\
\quad \text { No } \\
\text { Yes } \\
\text { Total }\end{array}$ & $\begin{array}{l}256(81.3 \%) \\
1244(85.4 \%) \\
1500(84.7 \%)\end{array}$ & $\begin{array}{l}59(18.7 \%) \\
212(14.6 \%) \\
271(15.3 \%)\end{array}$ & $\begin{array}{c}315(100.0 \%) \\
1456(100.0 \%) \\
1771(100.0 \%)\end{array}$ & 3.474 & 1 & .062 \\
\hline $\begin{array}{l}\text { Religion: How Often Attend } \\
\text { Religious Services } \\
\text { Not at All } \\
\text { One or More Times a } \\
\text { Year } \\
\text { Two or Three Times a }\end{array}$ & $\begin{array}{l}185(75.5 \%) \\
240(73.2 \%) \\
338(81.2 \%)\end{array}$ & $\begin{array}{l}60(24.5 \%) \\
88(26.8 \%) \\
78(18.8 \%)\end{array}$ & $\begin{array}{l}245(100.0 \%) \\
328(100.0 \%) \\
416(100.0 \%)\end{array}$ & 17.463 & 4 & $* .002$ \\
\hline
\end{tabular}




\begin{tabular}{|c|c|c|c|c|c|c|}
\hline $\begin{array}{l}\text { Month } \\
\text { Once a Week } \\
\text { More Than Once a Week } \\
\text { Total }\end{array}$ & $\begin{array}{l}520(83.5 \%) \\
503(80.1 \%) \\
1786(79.7 \%)\end{array}$ & $\begin{array}{l}103(16.5 \%) \\
125(19.9 \%) \\
\\
454(20.3 \%)\end{array}$ & $\begin{array}{l}623(100.0 \%) \\
628(100.0 \%) \\
2240(100.0 \%)\end{array}$ & & & \\
\hline $\begin{array}{l}\text { Religion: Importance of } \\
\text { Religion } \\
\text { Not Too Important } \\
\text { Somewhat Important } \\
\text { Very Important } \\
\text { Total }\end{array}$ & $\begin{array}{l}33(80.5 \%) \\
98(76.6 \%) \\
1657(79.9 \%) \\
1788(79.8 \%)\end{array}$ & $\begin{array}{l}8(19.5 \%) \\
30(23.4 \%) \\
416(20.1 \%) \\
454(20.2 \%)\end{array}$ & $\begin{array}{l}41(100.0 \%) \\
128(100.0 \%) \\
2073(100.0 \%) \\
2242(100.0 \%)\end{array}$ & .862 & 2 & .650 \\
\hline $\begin{array}{l}\text { Caregiving: Care of Grandkids- } \\
\text { 100 or More Hours } \\
\text { No } \\
\text { Yes } \\
\text { Total }\end{array}$ & $\begin{array}{l}853(80.8 \%) \\
550(76.8 \%) \\
1403(79.2 \%)\end{array}$ & $\begin{array}{l}203(19.2 \%) \\
166(23.2 \%) \\
369(20.8 \%)\end{array}$ & $\begin{array}{l}1056(100.0 \%) \\
716(100.0 \%) \\
1772(100.0 \%)\end{array}$ & 4.060 & 1 & .044 \\
\hline
\end{tabular}

\subsection{Association between Ever Had Depression and Independent Variables}

Table 2 presents the association between ever had depression and each independent variable. A Pearson Chisquaretest shows that age was associated with ever having depression (p-value .0001). For social support, marital status (p-value .0001), receiving help from relatives (p-value .002), and the number of times women get together with other people (p-value .022) were associated with ever having depression. However, there was no association between ever having depression and having relatives or good friends near (p-values .729, .058), nor for having relatives and/or friends that would help with future needs (p-value .062). While the frequency of attending religious services was associated with ever having depression ( $\mathrm{p}$-value .002), the importance of religion was not ( $\mathrm{p}$ value .650). Additionally, caregiving and physical health were both associated with ever having depression (pvalues .044, .0001).

\subsection{Predictors of Ever Had Depression}

Table 3 presents the predictors of ever had depression by selected independent variables. Age was a significant predictor of ever having depression. Furthermore, there was a significant difference within the age categories. Women who were in the 70 to 79 age group had a p-value of .003 . These individuals were $53.2 \%\{(100)(1-$ .468) \} less likely to have ever had depression than people in the 50-59 age group. Some aspects of social support were significant predictors of ever having depression. When compared to people who had never been married, married respondents were 50\% times (odds ratio .500) less likely to have ever had depression (p-value .007). None of the other social support measures were predictors of ever having depression ( $\mathrm{p}$-values >.08). The two religious measures and caregiving were not significant predictors of ever having depression ( $\mathrm{p}$-values >.2).

When compared to women who had rated themselves as having poor health, people who rated themselves as having excellent health were $86.5 \%$ (odds ratio .135) less likely to have ever had depression (p-value .0001) and people who rated their health as very good were $85.5 \%$ (odds ratio .145) less likely to have ever had depression (p-value .0001 ). Those who rated their health as good or fair were $74.1 \%$ (odds ratio .259) and 50.2\% (odds ratio .498) less likely, respectively (p-values .0001,.023).

Table 3.Logistic Regression of Ever Had Depression by Selected Independent Variables

\begin{tabular}{|c|c|c|c|c|}
\hline \multirow[b]{2}{*}{ Independent Variables } & \multicolumn{4}{|c|}{ Ever Had Depression } \\
\hline & P Value & $(\operatorname{Exp}) \mathrm{B}$ & Lower 95\% CI & Upper 95\% CI \\
\hline \multicolumn{5}{|l|}{ Age Group } \\
\hline 90 and Older & .899 & .869 & .099 & 7.612 \\
\hline $80-89$ & .222 & .564 & .224 & 1.415 \\
\hline $70-79$ & $* .003$ & .468 & .284 & .770 \\
\hline $60-69$ & .438 & .862 & .591 & 1.256 \\
\hline
\end{tabular}


Social Support: Marital Status

Married

Separated

*.007

Divorced

.059

.500

.480

.301

.224

$.813 \quad .493$

.416

.660

.387

.830

1.029

.127

\begin{tabular}{|c|c|c|c|c|}
\hline Social Support: Relatives Near & .774 & 987 & .904 & 1.078 \\
\hline Social Support: Good Friends Near & .545 & .972 & .887 & 1.065 \\
\hline \multicolumn{5}{|c|}{$\begin{array}{l}\text { Social Support: Number of Times Get } \\
\text { Together with People }\end{array}$} \\
\hline Day & .242 & .703 & .390 & 1.268 \\
\hline Week & .556 & .883 & .583 & 1.337 \\
\hline Every Two Weeks/Bi-Weekly & .088 & .331 & .093 & 1.178 \\
\hline Month & .211 & .719 & .429 & 1.205 \\
\hline Year & .946 & .971 & 22 & 2.239 \\
\hline \multicolumn{2}{|c|}{$\begin{array}{l}\text { Social Support: Relatives/Friends Help } .176 \\
\text { with Future Needs }\end{array}$} & 1.073 & .969 & 1.188 \\
\hline $\begin{array}{l}\text { Social Support: Receive Help fror } \\
\text { Relatives }\end{array}$ & .093 & .874 & .747 & 1.023 \\
\hline \multicolumn{5}{|l|}{$\begin{array}{l}\text { Religion: How OftenAttend Religious } \\
\text { Services }\end{array}$} \\
\hline More Than Once a Week & .418 & 1.299 & .689 & 2.449 \\
\hline Once a Week & .982 & 1.007 & .535 & 1.895 \\
\hline Two or Three Times a Month & .839 & .932 & .474 & 1.834 \\
\hline One or More Times a Year & .335 & 1.371 & .722 & 2.606 \\
\hline \multicolumn{5}{|l|}{ Religion: Importance of Religion } \\
\hline Very Important & .727 & .817 & .263 & 2.540 \\
\hline Somewhat Important & .997 & .998 & .291 & 3.416 \\
\hline $\begin{array}{l}\text { Caregiving: Care of Grandkids-100 c } \\
\text { More Hours }\end{array}$ & 289 & .957 & .882 & 1.038 \\
\hline \multicolumn{5}{|l|}{ Physical Health } \\
\hline Excellent & $* .0001$ & .135 & .054 & .341 \\
\hline Very Good & $* .0001$ & .145 & .073 & .289 \\
\hline Good & $* .0001$ & .259 & .142 & .472 \\
\hline Fair & $* .023$ & .498 & .273 & .907 \\
\hline
\end{tabular}

\begin{tabular}{|c|c|c|c|c|}
\hline Social Support: Relatives Near & .774 & .987 & .904 & 1.078 \\
\hline Social Support: Good Friends Near & .545 & .972 & .887 & 1.065 \\
\hline \multicolumn{5}{|l|}{$\begin{array}{l}\text { Social Support: Number of Times Get } \\
\text { Together with People }\end{array}$} \\
\hline Day & .242 & .703 & .390 & 1.268 \\
\hline Week & .556 & .883 & .583 & 1.337 \\
\hline Every Two Weeks/Bi-Weekly & .088 & .331 & .093 & 1.178 \\
\hline Month & .211 & .719 & .429 & 1.205 \\
\hline Year & .946 & .971 & 22 & 2.239 \\
\hline \multicolumn{2}{|c|}{$\begin{array}{l}\text { Social Support: Relatives/Friends Help .176 } \\
\text { with Future Needs }\end{array}$} & 1.073 & .969 & 1.188 \\
\hline $\begin{array}{l}\text { Social Support: Receive Help from } \\
\text { Relatives }\end{array}$ & .093 & .874 & .747 & 1.023 \\
\hline \multicolumn{5}{|l|}{$\begin{array}{l}\text { Religion: How OftenAttend Religious } \\
\text { Services }\end{array}$} \\
\hline More Than Once a Week & .418 & 1.299 & 689 & 2.449 \\
\hline Once a Week & .982 & 1.007 & .535 & 1.895 \\
\hline Two or Three Times a Month & .839 & .932 & .474 & 1.834 \\
\hline One or More Times a Year & .335 & 1.371 & .722 & 2.606 \\
\hline \multicolumn{5}{|l|}{ Religion: Importance of Religion } \\
\hline Very Important & .727 & .817 & .263 & 2.540 \\
\hline Somewhat Important & .997 & .998 & .291 & 3.416 \\
\hline $\begin{array}{l}\text { Caregiving: Care of Grandkids-100 or } \\
\text { More Hours }\end{array}$ & .289 & .957 & .882 & 1.038 \\
\hline \multicolumn{5}{|l|}{ Physical Health } \\
\hline Excellent & $* .0001$ & .135 & .054 & .341 \\
\hline Very Good & $* .0001$ & .145 & .073 & .289 \\
\hline Good & $* .0001$ & .259 & .142 & .472 \\
\hline Fair & $* .023$ & .498 & .273 & .907 \\
\hline
\end{tabular}

1.339

1.126

\subsection{Summary of Associations and Predictors of Depression and Selected Independent Variables}

There were many similarities in the bivariate analyses, as illustrated in Table 4. For both measures of depression, age, marital status, receiving help from relatives, the number of times one gets together with other people, how often a woman attends religious services, and physical health all had significant associations. Caregiving, which had a significant association with ever having depression, did not have a significant association with feeling depressed in the past year. Having relatives near, good friends near, having relatives and/or friends who would help with future needs, and the importance of religion did not have significant associations with ever having depression or feeling depressed in the past year. Table 4 shows the similarities between the multiple logistic regression analyses. Age, marital status, and physical health were the only three significant predictors of ever having depression and feeling depressed in the past year. No other variable measures were significant predictors of depression, when controlling for all the variables. 
Table 4: Summary of Multiple Logistic Regression Results for Women in the Sample

\begin{tabular}{lll}
\hline Independent Variable & $\begin{array}{l}\text { Depression } \\
\text { Ever Had Depression }\end{array}$ & $\begin{array}{l}\text { Felt Depressed in Past Year } \\
\text { Xge }\end{array}$ \\
\hline Social Support & $\mathrm{X}$ \\
\hline Marital Status & $\mathrm{X}$ & $\mathrm{X}$ \\
Receive Help from Relatives & & \\
$\begin{array}{l}\text { Relatives Near } \\
\text { Good Friends Near }\end{array}$ & \\
Number of Times Get Together with & \\
Other People & & \\
Relatives/Friends Help with Future & \\
Needs & \\
\hline Religion & \\
\hline How Often Attend Religious & \\
Services & \\
Importance of Religion & $\mathrm{X}$ \\
Caregiving & \\
\hline Physical Health & $\mathrm{X}$ \\
\hline
\end{tabular}

Note: $\mathrm{X}$, variable was significant for $(\mathrm{p} \leq .05)$ the respective depression categories.Results indicated that in the general population age, social support, and physical health can inform the likelihood of depression.

\subsection{Discussion}

This study sought to determine the risk and protective factors associated with depression among a sample of older, African American women in the United States. The study had the following research questions: (1) what is the relationship between age and depression, (2)what is the influence of social support on depression, (3) what is the relationship between religion and depression, (4) what is the relationship between caregiving and depression, (5) what is the influence of physical health on depression, and (6) what is the joint impact of age, social support, religion, caregiving, and physical health on depression. Ultimately, this research explored the association and/or predictors of the independent selected variables with ever having depression and feeling depressed in the past year. Guided by intersectionality and social construction theories, several factors that may have had an impact on depression were studied.

The first research hypothesis, which was the prevalence rate of depression will differ by age, was supported. These data suggest that there is variation in age groups with respect to depression. In other words, depending on the age group of an individual, age can be a source of risk or protection for depression.

The second research hypothesis was that the six types of social support, individually, will be associated with depression. Under the categories of social support, marital status, receiving help from relatives, and the number of times a woman gets together with other people were associated with depression. However, relatives near, good friends near, and having relatives/friends help with future needs were not associated with depression. That is, social support can be a source of risk or protection for depression.

The third research hypothesis, which stated that religion will be associated with depression, was supported for how often one attends religious services, but rejected for the importance of religion. In other words, how often one attends religious services may serve as a risk or protective factor for depression. The fourth research hypothesis stated that caregiving will be associated with depression. This research hypothesis was supported for ever had depression but rejected for felt depressed in the past year. Caregiving may or may not be a source of risk or protection for depression. The fifth research hypothesis, which was physical health will be associated with depression, was supported. This suggests that physical health can be a source of risk or protection for depression.

With regard to the sixth and final research hypothesis regarding age, social support, religion, caregiving, and physical health independently and/or jointly predicting depression, only age, marital status, and physical health jointly remained significant predictors of depression, after controlling for all the other variables in the model. In other words, age, marital status, and physical health were possible sources of risk or protection for depression. Receiving help from relatives remained significant for feeling depressed in the past year. However, receiving help from relatives was attenuated for ever having depression, after controlling for all the other variables in the model. 
In summary, age, physical health, and marital status, were all predictors of whether or not a woman had ever had depression and whether or not a woman felt depressed in the past year. That is, these factors are possible sources of risk or protection for ever having depression or feeling depressed in the past year. Basically, it is possible that age, health and illness, and marital status can contribute to depression. These findings were consistent with research that states that age, social support, and physical health can inform the likelihood of depression (Kelley-Moore \& Ferrara, 2005; Lo et al., 2010; Mair, 2010).

\subsection{Implication for Practice}

This study has implications at the micro, meso, and macro levels in relation to social work research and theory, policy, and practice. First, additional areas for research and theories are discussed. Next, specific policy implications are suggested, relative to the Affordable Care Act. Lastly, suggestions for social work practice and education are provided. Several areas of research should be expanded upon. Future research should focus on how being in multiple roles (e.g., caregiver, employee, volunteer, student, community leader) (Baker \& Silverstein, 2008b) may influence women's mental health status, particularly among African American women. Studies could include a cross-cultural comparison between older African American women in urban environments and other women of color. Though support group was not a factor examined in this study, it has been found to reduce stress and ease isolation (Blustein, Chan, \& Guanais, 2004), thus further research including aspects of support groups may be necessary, specifically as it relates to helping to treat depression among African American women and other people of color. Furthermore, in order to compare individuals in different situations in a systematic way, more cross-cultural nationally representative data, like the Health and Retirement Study is needed. Although this study uses a cross-sectional analysis, using a longitudinal analysis (Mair, 2010) for the data could be beneficial to suggest causal pathways and to illustrate changes over different periods in time. Studying the social variation within groups (Warner \& Brown, 2011) would also help to better understand the process leading to health differences with age.

More studies need to focus on the connection between age and depression, marital status and depression, and physical health and depression, linking each individually and jointly. While focusing on these connections, the next steps would include targeting specific treatment options for ethnic and minority populations, particularly women of color. While treatment is available for these groups, they are often underutilized or not utilized at all for many different reasons including lack of cultural awareness and sensitivity (Min, 2005). Mixed methods approaches are recommended in order to investigate the complete account of barriers to treatment.

Mental health is a broad topic that needs much more research, especially among older generations of color. Because there are so many different types of mental health issues, future studies could benefit from not only researching those issues, but also factors that may intersect with mental health challenges including substance abuse and chronic diseases among the aged. Prevention may or may not be possible, but studying mental health issues such as depression more in-depth will at least allow researchers to see if there is a pattern of how and when it develops and what can alleviate the issue and help maintain better health.

While most of the major theoretical perspectives have been applied to White European males in the United States, they can gain value from the inclusion of older, African American, community-dwelling women. For instance, the contextual perspective of intersectionality and social construction theory takes into account the physical, cognitive, personality, and social worlds of individuals which were core components in this study in relation to depression among African American women (Bowleg, 2012; Otubanjo, 2012). In alignment with these theories, factors such as age, social support, and physical health can be used as buffers or protective factors for depression in older, African American women. Findings from this study can inform not only perspectives from intersectionality and social construction but also existing theories such as the sociocultural theory by Lev Semenovich Vygotsky and the bioecological approach by Urie Bronfenbrenner (Feldman, 2003).

\section{References}

Abdel-Rahman, E. (2012). Depression in the elderly. New York: Nova Science Publisher, Inc. Abdalati, H. (1998). Islam in focus. Kuala Lumpur: Islamic Book trust.

Administration on Aging (2012). A Profile of older American 2011. Retrieved from

http://www.aoa.gov/Aging_Statistics/Profile/2011/2.aspx

Adkinson-Bradley, C., Johnson, D. Sanders, J. L., Duncan, L., \& Holcomb-McCoy, C. (2005). Forging a collaborative relationship between the black church and counseling profession. (Issues and insights). Counseling and Values, 49, 147-154.

Al-Jawad, M., Rashid, A. K., \& Narayan, K. A. (2007). Prevalence of undetected cognitive impairment and depression in residents of an elderly care home. Medical Journal of Malaysia, 62(5), 375-379

Allen, R. S., Phillips, L. L., Roff, L. L., Cavanaugh, R., \& Day, L. (2008).Religiousness/spirituality and mental health among older male inmates. The Gerontologist, 48(5), 692-697. 
American Psychiatric Association (2013). Diagnostic and Statistical Manual of Mental Disorders Fifth Ediction- (DSM-5). Washington, DC: American Psychiatric Association.

American Psychiatric Association (1987). Diagnostic and Statistical Manual of Mental Disorders Third Ediction-Revised: DSM-III-R. Washington, DC: American Psychiatric Association.

American Psychological Association (2009). Positive aging act. Retrieved from http://www.apa.org/about/gr/issues/aging/positive-aging-facts.aspx

Aneshensel, C. S., Wight, R. G., Miller-Martinez, D., Botticello, A. L., Karlamangla, A. S., \& Seeman, T. E. (2007). Urban neighborhoods and depressive symptoms among older adults. The Journals of Geron tology, 62B (1), S52-S59.

Bailly, N., \&Roussiau, N. (2010). The Daily Spiritual Experiences Scale (DSES):Validation of the short form in an elderly French population. Canadian Journal on Aging, 29(2), 223-231. doi: $10.1017 / \mathrm{S} 0714980810000152$

Baker, L. A., \& Silverstein, M. (2008a). Depressive symptoms among grandparents raising grandchildren: The impact of participation in multiple roles. Journal of Intergenerational Relationships, 6(3), 285- 304. doi: 10.1080/15350770802157802

Baker, L. A., \& Silverstein, M. (2008b). Preventive health behaviors among grandmothers raising grandchild dren. The Journals of Gerontology, 63B(5), S304-S311.

Barg, F. K., Huss-Ashmore, R., Wittink, M. N., Murray, G. F., Bogner, H. R., \& Gallo, J. (2006). A mixedmethods approach to understanding loneliness and depression in older adults. The Journals of Gerontology, 61B(6), S329-S339.

Bazargan, M., Bazargan-Hejazi, S., \& Baker, R. S. (2005). Treatment of self-reported

depression among Hispanics and African Americans. Journal of Health Care for the Poor and Underserved, 16(2), 328-344.

Beauboeuf-Lafontant, T. (2008). Listening past the lies that make us sick: A voice-

centered analysis of strength and depression among black women. Qualitative Sociology, 31, 391-406. doi: 10.1007/s11133-008-9113-1

Beauboeuf-Lafontant, T. (2005). Keeping up appearances, getting fed up: The embodiment of strength among African American women. Meridians, 5(2), 104-123.

Berrios, G. E. (1988). Melancholia and depression during the nineteenth century. British Journal of Psychiatry, 153, 298-394. 114

Black, H. K., Gitlin, L., \& Burke, J. (2011). Context and culture: African Americanelders' experiences of depression. Mental Health, Religion \& Culture, 14(7), 643-657. doi: 10.1080/13674676.2010.505233

Black, H. K., \& Rubinstein, R. L. (2009). The effect of suffering on generativity:Accounts of elderly African American men. The Journals of Gerontology, 64B(2), 296-303.

Black, H. K., White, T., \&Hannum, S. M. (2007). The lived experience of depression in elderly African American women. The Journals of Gerontology, 62B (6), S392-S398.

Bluth, K., Campo, R. A., Futch, W. S., \& Gaylord, S. A. (2016). Age and gender differences in the associations of self-compassion and emotional well-being in a large adolescent sample. Journal of Youth and Adolescence, 46, 840-853. doi.10.1007/s10964-016-0567-2

Blustein, J., Chan, S., \&Guanais, F. C. (2004). Elevated depressive symptoms among caregiving grandparents. Health Services Research, 39(6 Pt 1), 1671-1690. doi: 10.1111/j.1475- $\quad$ 6773.2004.00312.x

Bogenschneider, K. (1998). Building resiliency and reducing risk: What youth need from families and communities to succeed. Madison, WI: Cooperative Extension Publishing Operations.

Bogner, H. R., Morales, K. H., Post, E. P., \& Bruce, M. L. (2007). Diabetes, depression, and death: A randomized controlled trial of a depression treatment program for older adults based in primary care (PROSPECT). Diabetes Care, 30(12), 3005-3010.

Bschor, T., Bauer, M., \& Adli, M. (2014). Chronic and treatment resistant depression. Arzteblatt International, 111, 766-776. doi.10.3238/arztebl.2014.0766

Bowleg, L. (2012). The problem with the phrase women and minorities: Intersectionality an important theoretical framework for public health. American Journal of Public Health, 102(7), 1267-1273. doi: 10.2015/AJPH.2012.300750

Bowles, J., Brooks, T., Hayes-Reams, P., Butts, T., Myers, H., Allen, W., \& Kington, R. S. (2000). Frailty, family, and church support among urban African American elderly. Journal of Health Care for the Poor and Underserved, 11(1), 87-99.

Briggs, W. P., Magnus, V. A., Lassiter, P., Patterson, A., \& Smith, L. (2011). Substance use, misuse, and abuse among older adults: Implications for clinical mental health counselors. Journal of Mental Health Counseling, 33(2), 112-127.

Calasanti, T. (2008). A feminist confronts ageism. Journal of Aging Studies, 22, 152-157. doi: 10.1016/j.jaging.2007.12.009 
Canda, E. R., Nakashima, M., \& Furman, L. D. (2004). Ethical considerations about spirituality in social work: Insights from a national qualitative survey. Families in Society: The Journal of Contemporary Services, 85(1), 27-35.

Centers for Disease Control and Prevention (2018). An estimated 1 in 10 adults in the U.S. report depression. Retrieved from http://www.cdc.gov/Features/dsDepression/

Charatan, F. (1975). Depression in old age. New York State Journal of Medicine 75(14),2505-2509.

Chumbler, N. R., Cody, M., Booth, B. M., \& Beck, C. K. (2001). Rural-urban differences in service use for memory-related problems in older adults. The Journal of Behavioral Health Services \& Research, 28(2), 212-221.

Coleman, P. G., McKiernan, F., Mills, M., \& Speck, P. (2007). In sure and uncertain faith: Belief and coping with loss of spouse in later life. Aging \& Society, 27, 869-890. doi: 10.1017/S0144686X07006551

Council on Social Work Education, Gero-Ed Center (2013). Why should I consider a career working with older adults? Retrieved from

http://www.cswe.org/CentersInitiatives/GeroEdCenter/Students/LearnMore/WhyGeroSocialWork.aspx

Crenshaw, K. (1991). Mapping the margins: intersectionality, identity politics, and violence against women of color. Stanford Law Review,43(6): 1241-1299.

Davey-Rothwell, M. A., Stewart, J., Vadnais, A., Braxton, S. A., \&Latkin, C. A. (2017). The role of partner support among women with depressive symptoms. Community Mental Health Journal, 53, 415-419.

Dilworth-Anderson, P., Goodwin, P. Y., \& Williams, S. W. (2004). Can culture help explain the physical health effects of caregiving over time among African American caregivers? The Journals of Gerontology, $59 B(3)$, S138-S145.

Eldercare Workforce Alliance (2012). Geriatrics workforce shortage: A looming crisis for our families. (Issue Brief) Washington, DC: Eldercare Workforce Alliance. Retrieved from

http://www.eldercareworkforce.org/research/issue-briefs/research:geriatrics-workforce-shortage-a-looming-crisisfor-our-families/\#_ednref6

Engstrom, M. (2008). Involving caregiving grandmothers in family interventions when mothers with substance use problems are incarcerated. Family Process, 47(3), 357-371.

Erikson, E. H. (1982). The life cycle completed. New York: W.W. Norton \& Company.

Feldman, R. (2003). Development across the Life Span. Upper Saddle River, NJ: Prentice Hall.

Frank, L. B., Matza, L. S., Revicki, D. A., \& Chung, J. Y. (2005). Depression and health-related quality of life for low-income African-American women in the U.S. Quality of Life Research, 14, 2293-2301. doi: $10.1007 / \mathrm{s} 11136-005-6541-1$

Furner, S. E., Wallace, K., Arguelles, L., Miles, T., \& Goldberg, J. (2006). Twin study of depressive symptoms among older African-American women. The Journals of Gerontology, $61 B$ (6), P355-P361.

Gatz, M., \& Fiske, A. (2003). Aging women and depression. Professional Psychology: Research and Practice, 34(1), 3-9. doi: 10.1037/0735-7028.34.1.3

Ghods, B. K., Roter, D. L., Ford, D. E., Larson, S., Arbelaez, J. J., \& Cooper, L. A. (2008). Patient-physician communication in the primary care visits of African Americans and whites with depression. Journal of General Internal Medicine, 23(5), 600-606. doi: 10.1007/s11606-008-0539-7

Gibson, P. A. (2005). Intergenerational parenting from the perspective of African American grandmothers. Family Relations, 54(2), 280-297.

Gibson, P. A. (2002). African American grandmothers as caregivers: Answering the call to help their grandchildren. Families in Society, 83(1), 35-43.

Gilbert, D. J., Harvey, A. R., \& Belgrave, F. Z. (2009). Advancing the Africentric paradigm shift discourse: Building toward evidence basedAfricentric interventions in social work practice with African Ameri cans. Social Work, 54(3), 243-252.

Givens, J. L., Katz, I. R., Bellamy, S., \& Holmes, W. C. (2007). Stigma and the acceptability of depression treatments among African Americans and whites. Journal of General Internal Medicine, 22, 1292- 1297. doi: 10.1007/s11606-007-0276-3

Goodman, C., \& Silverstein, M. (2002). Grandmothers raising grandchildren: Family structure and well-being in culturally diverse families. The Gerontologist, 42(5), 676-689.

Hindman, S. (2009) Positive aging act returns to Congress. Silver Planet Online. Retrieved from http://www.silverplanet.com/health/emotional-mental-health/positive-aging-act-returns-con gress/55434

Hodge, D. R., \& Limb, G. E. (2010). Conducting spiritual assessments with Native Americans: Enhancing cultural competency in social work practice courses. Journal of Social Work Education, 46(2), 265- $284 . \quad$ doi: 10.5175/JSWE.2010.200800084

Hodge, D. R., \& Williams, T. R. (2002). Assessing African American spirituality with spiritual ecomaps. Families in Society, 83(5/6), 585-595. 
Hsu, H. C, \& Tung, H. J (2010). What makes you good and happy? Effects of internal and externalresources to adaptation and psychological well-being for the disabled elderly in Taiwan. Aging \& Mental Health, 14(7), 851-860.

Hughes, M. E., Waite, L. J., LaPierre, T. A., \& Luo, Y. (2007). All in the family: The impact of caring for grandchildren on grandparents' health. The Journals of Gerontology, 62B(2), S108-S119.

Hunn, V. L., \& Craig, C. D. (2009). Depression, sociocultural factors, and African American women. Journal of Multicultural Counseling and Development, 37(2), 83-93.

Jang, Y., Borenstein, A. R., Chiriboga, D. A., \& Mortimer, J. A. (2005). Depressive symptoms among African American and white older adults. The Journals of Gerontology, 60B (6), P313P319.

Johnson, K. S., Tulsky, J. A., Hays, J. C., Arnold, R. M., Olsen, M. K., Lindquist, J. H., \&Steinhauser, K. E. (2011). Which domains of spirituality are associated with anxiety and depression in patients with advanced illness? Journal of General Internal Medicine, 26(7), 751-758. doi: 10.1007/s11606-011- 1656-2

Kaslow, N. J., Price, A. W., Wyckoff, S., Grall, M. B., Sherry, A., \& Young, S. (2004). Person factors associated with suicidal behavior among African American women and men. Cultural Diversity and Ethnic Minority Psychology, 10(1), 5-22. doi: 10.1037/1099-9809.10.1.5

Kelley-Moore, J. A., \& Ferraro, K. F. (2005). A 3-D model of health decline: Disease, disability, and depress sion among black and white older adults. Journal of Health and Social Behavior, 46(4), 376-391.

Lach, H. W., Chang, Y-P., \& Edwards, D. (2010). Can older adults with dementia accurately report depression using brief forms? Reliability and validity of the Geriatric Depression Scale. Journal of Gerontological Nursing, 36(5), 30-37.

Lazear, K. J., Pires, S. A., Isaacs, M. R., Chaulk, P., \& Huang, L. (2008). Depression among low-income women of color: Qualitative findings from cross-cultural focus groups. Journal of Immigrant Minority Health, 10 , 127-133. doi: 10.1007/s10903-007-9062-x

Levin, J., Fox, J. A., \& Forde, D. R. (2010). Elementary statistics in social research (11 $1^{\text {th }}$ edition). Boston, MA: Allyn \& Bacon.

Li, N., Pang, L., Chen, G., Song, X., Zhang, J., \& Zheng, X. (2011). Risk factors for depression in older adults in Beijing. Canadian Journal of Psychiatry, 56(8), 466-473.

Lipscomb, R. C. (2005). The challenges of African American grandparents raising their grandchildren. Race, Gender \& Class, 12(2), 163-177.

Lo, C., Lin, J., Gagliese, L., Zimmermann, C., Mikulincer, M., \& Rodin, G. (2010). Age and depression in patients with metastatic cancer: The protective effects of attachment security and spiritual wellbeing. Aging \& Society, 30, 325-336. doi: 10.1017/S0144686X09990201

Lowis, M. J., Edwards, A. C., \& Burton, M. (2009). Coping with retirement: Well-being, health, and religion. The Journal of Psychology, 143(4), 427-448.

Lum, T. Y., \&Vanderaa, J. P. (2010). Health disparities among immigrant and non-immigrant elders: The association of acculturation and education. Journal of Immigrant Minority Health, 12, 743-753. doi: 10.1007/s10903-008-9225-4

Mahoney, D. F., Cloutterbuck, J., Neary, S., \& Zhan, L. (2005). African American, Chinese, and Latino family caregivers' impressions of the onset and diagnosis of dementia: Cross-cultural similarities and differences. The Gerontologist, 45(6), 783-792.

Mair, C. A. (2010). Social ties and depression: An intersectional examination of black and white communitydwelling older adults. Journal of Applied Gerontology, 29(6), 667-696. doi: 10.1177/0733464809350167

Martin, S. S. (2009). Illness of the mind or illness of the spirit? Mental health-related conceptualization and practices of older Iranian immigrants. Health \& Social Work, 34(2), 117-126.

Mills, T. L., Alea, N. L., \& Cheong, J. A. (2004). Differences in the indicators of depressive symptoms among a community sample of African American and Caucasian older adults. Community Mental Health Journal, 40(4), 309-331.

Min, J. W. (2005). Cultural competency: A key to effective future social work with racially and ethnically di verse elders. Families in Society, 86(3), 347-358.

Mojtabai, R., \&Olfson, M. (2004). Major depression in community-dwelling middle-aged and older adults: Prevalence and 2- and 4-year follow-up symptoms. Psychological Medicine, 34(4), 623-634. doi: $10.1017 / \mathrm{S} 0033291703001764$

Momtaz, Y. A., Hamid, T. A., Ibrahim, R., Yahaya, N., \& Tyng, C. S. (2011). Moderating effect of religiosity on the relationship between social isolation and psychological wellbeing. Mental Health, Religion \& Culture, 14(2), 141-156.

Musil, C. M., Warner, C. B., Zauszniewski, J. A., Jeanblanc, A. B., \& Kercher, K. (2006). Grandmothers, caregiving, and family functioning. The Journals of Gerontology, $61 B$ (2), S89-S98. 
Nadeem, E., Lange, J. M., Edge, D., Fongwa, M., Belin, T., \& Miranda, J. (2007). Does stigma keep poor $\quad$ young immigrant and U.S.-born black and Latina women from seeking mental health care? Psychiatric Services, 58(12), 1547-1554.

National Association of Social Workers (2008). NASW Code of Ethics (Guide to the Everyday Professional Conduct of Social Workers). Washington, DC: NASW.

National Gerontological Nursing Association. (2011). Sens. Collins and Mikulski introduce positive aging act. Retrieved from http://www.ngna.org/news/other-news/140-positive-aging-act.html

Ness, J., Cirillo, D. J., Weir, D. R., Nisly, N. L., \& Wallace, R. B. (2005). Use of complementary medicine in older Americans: Results from the Health and Retirement Study. The Gerontologist, 45(4), 516-524.

Nicolaidis, C., Timmons, V., Thomas, M. J., Waters, S., Wahab, S., Mejia, A., \& Mitchell, S. R. (2010). "You don't go tell white people nothing": African American women's perspectives on the influence of violence and race on depression and depression care. American Journal of Public Health, 100(8), $1470-1476$.

O’Malley, A. S., Forrest, C. B., \& Miranda, J. (2003). Primary care attributes and care for depression among lowincome African American women. American Journal of Public Health, 93(8), 1328-1334.

Otubanjo, O. (2012). Embedding theory in corporate identity through the social construction lens. International Journal of Business and Management, 7(22), 62-75. doi: 10.5539/ijbm. v7n22p62

Payne, M. (2005). Modern social work theory ( $3^{\text {rd }}$ edition). Chicago, IL: Lyceum Books.

Pedraza, O., Dotson, V. M., Willis, F. B., Graff-Radford, N. R., \& Lucas, J. A. (2009). Internal consistency and test-retest Stability of the Geriatric Depression Scale-Short Form in African American older adults. Journal of Psychopathology and Behavioral Assessment, 31, 412-416. doi: 10.1007/s10862-008-9123-z

Rashid, A., Azizah, M., \& Rohana, S. (2012). Risk factors for depressive symptoms among elderly Malays living in rural north Malaysia. Indian Journal of Gerontology, 26(4), 462- 473.

Rozario, P. A., Chadiha, L. A., Proctor, E. K., Morrow-Howell, N. (2008). Predicting theinfluence of social resources on African American wife and daughter caregivers' depressive symptoms. Journal of Family Issues, 29(3), 317-333. doi: 10.1177/0192513X07306983

Rubin, A., \& Babbie, E. (2011). Research methods for social work. Belmont, CA: Brooks/Cole.

Ruiz, D. S., \& Zhu, C. W. (2004). Families maintained by African American grandmothers: Household composition and childcare experiences. Western Journal of Black Studies, 28(3), 415-423.

Salimah, O., Rahmah, M.A., Rosdinom, R., \& Shamsul Azhar, S. (2008). A case control study on factors that influence depression among the elderly in Kuala Lumpur Hospital and Universiti Kebangsaan Malaysia Hospital. Medical Journal of Malaysia, 63(5), 395-400.

Schieman, S., \&Plickert, G. (2007). Functional limitations and changes in levels of depression among older adults: A multiple-hierarchy stratification perspective. The Journals of Gerontology, 62B(1), S36-S42.

Schulman, E., Gairola, G., Kuder, L., \& McCulloch, J. (2002). Depression and associatedcharacteristics among community-based elderly people. Journal of Allied Health, 31(3), 140-146.

Sirey, J. A., Bruce, M. L., \&Alexopoulos, G. S. (2005). The Treatment Initiation Program: An intervention to improve depression outcomes in older adults. The American Journal of Psychiatry, 162(1), 184-186.

Skarupski, K. A., de Leon, C. F. M., Bienias, J. L., Barnes, L. L., Everson-Rose, S. A., Wilson, R. S., \&Ev ans, D. A. (2005). Black-white differences in depressive symptoms among older adults over time. The Journals of Gerontology, 60B, 3, P136-P142.

Smith, T. B., McCullough, M. E., \& Poll, J. (2003). Religiousness and depression: Evidence for a main effect and the moderating influence of stressful life events. Psychological Bulletin, 129(4), 614-636. doi: 10.1037/0033-2909.129.4.614

Spence, N. J., Adkins, D. E., \& Dupre, M. E. (2011). Racial differences in depression rajectories among older women: Socioeconomic, family, and health influences. Journal of Health and Social Behavior, 52(4), 444459. doi: $10.1177 / 0022146511410432$

Sreevani, R., \& Reddemma, K. (2012). Depression and spirituality: a qualitative approach. International Journal of Nursing Education, 4(1), 90-93.

Sriwattanakomen, R., McPherron, J., Chatman, J., Morse, J. Q., Martire, L. M., Karp, J. F.,...Reynolds III, C. F. (2010). A comparison of the frequencies of risk factors for depression in older black and white participants in a study of indicated prevention. International Psychogeriatrics, 22(8), 1240-1247. doi: $10.1017 /$ S1041610210001523

Steffens, D. C., Fisher, G. G., Langa, K. M., Potter, G. G., \&Plassman, B. L. (2009). Prevalence of depression among older Americans: The aging, demographics and memory study. International Psychogeriatrics, 21(5), 879-888. doi: 10.1017/S1041610209990044

U.S. Department of Health and Human Services (2018). Mental health culture, race, ethnicity: a supplement to mental health. A report of the Surgeon General. Rockville MD: Author.

U.S. Department of Health and Human Services, National Institutes of Health, National Institute on Aging. (2002). Growing older in America: The Health and Retirement Study. Retrieved from http://hrsonline.isr.umich.edu/ 
Waite, R., \& Killian, P. (2008). Health beliefs about depression among African American women. Perspectives in Psychiatric Care, 44(3), 185-195.

Walby, S., Armstrong, J., \& Strid, S. (2012). Intersectionality and the quality of the gender equality architecture. Social Politics, 19(4), 446-481. doi: 10.1093/sp/jxs015

Warner, D. F., \& Brown, T. H. (2011). Understanding how race/ethnicity and gender define age-trajectories of disability: An intersectionality approach. Social Science \& Medicine, 72, 1236-1248. doi: 10.1016/j.socscimed.2011.02.034

Washington, O. G. M., Moxley, D. P., Garriott, L., Weinberger, J. P. (2009). Five dimensions of faith and spiritually of older African American women transitioning out of homelessness. Journal of Religion and Health, 48, 431-444. doi: 10.1007/s10943-008-9198-6

Winner, J. M., \& Tilly, J. (2012). Population ageing in the United States of America: implications for public programmes. International Journal of Epidemiology. 31 (4), 776- 781.

Wittink, M. N., Joo, J. H., Lewis, L. M., \&Barg, F. K. (2009). Losing faith and using faith: Older African Americans discuss spirituality, religious activities, and depression. Journal of General Internal Medicine, 24(3), 402-407. doi: 10.1007/s11606-008-0897-1

World Health Organization (2012). Depression. Retrieved from: http://www.who.int/mediacentre/factsheets/fs369/en/

Zalaquett, C. P., \&Stens, A. N. (2006). Psychosocial treatments for major depression and dysthymia in older adults: A review of the research literature. Journal of Counseling and Development: JCD, 84(2), 192-201. 